\title{
Convergence Theorems of Three-Step Iterative Scheme for a Finite Family of Uniformly Quasi-Lipschitzian Mappings in Convex Metric Spaces
}

\author{
Tian You-xian and Yang Chun-de \\ Institute of Applied Mathematics, Chongqing University of Posts and Telecommunications, \\ Chongqing 400065, China \\ Correspondence should be addressed to Tian You-xian, tianyx@cqupt.edu.cn \\ Received 9 December 2008; Accepted 25 March 2009 \\ Recommended by Nanjing Huang
}

We consider a new Noor-type iterative procedure with errors for approximating the common fixed point of a finite family of uniformly quasi-Lipschitzian mappings in convex metric spaces. Under appropriate conditions, some convergence theorems are proved for such iterative sequences involving a finite family of uniformly quasi-Lipschitzian mappings. The results presented in this paper extend, improve and unify some main results in previous work.

Copyright (C) 2009 T. You-xian and Y. Chun-de. This is an open access article distributed under the Creative Commons Attribution License, which permits unrestricted use, distribution, and reproduction in any medium, provided the original work is properly cited.

\section{Introduction and Preliminaries}

Takahashi [1] introduced a notion of convex metric spaces and studied the fixed point theory for nonexpansive mappings in such setting. For the convex metric spaces, Kirk [2] and Goebel and Kirk [3] used the term "hyperbolic type space" when they studied the iteration processes for nonexpansive mappings in the abstract framework. For the Banach space, Petryshyn and Williamson [4] proved a sufficient and necessary condition for Picard iterative sequences and Mann iterative sequence to converge to fixed points for quasi-nonexpansive mappings. In 1997, Ghosh and Debnath [5] extended the results of [4] and gave the sufficient and necessary condition for Ishikawa iterative sequence to converge to fixed points for quasi-nonexpansive mappings. Liu [6-8] proved some sufficient and necessary conditions for Ishikawa iterative sequence and Ishikawa iterative sequence with errors to converge to fixed point for asymptotically quasi-nonexpansive mappings in Banach space and uniform convex Banach space. Tian [9] gave some sufficient and necessary conditions for an Ishikawa iteration sequence for an asymptotically quasi-nonexpansive mapping to converge to a fixed point in convex metric spaces. Very recently, Wang and Liu [10] gave some iteration sequence 
with errors to approximate a fixed point of two uniformly quasi-Lipschitzian mappings in convex metric spaces. The purpose of this paper is to give some sufficient and necessary conditions for a new Noor-type iterative sequence with errors to approximate a common fixed point for a finite family of uniformly quasi-Lipschitzian mappings in convex metric spaces. The results presented in this paper generalize, improve, and unify some main results of [1-14].

First of all, let us list some definitions and notations.

Let $T$ be a given self mapping of a nonempty convex subset $C$ of an arbitrary real normed space. The sequence $\left\{x_{n}\right\}_{n=0}^{\infty}$ defined by

$$
\begin{gathered}
x_{0} \in C, \\
x_{n+1}=\alpha_{n} x_{n}+\beta_{n} T y_{n}+\gamma_{n} u_{n}, \quad n \geq 0, \\
y_{n}=a_{n} x_{n}+b_{n} T z_{n}+c_{n} v_{n}, \\
z_{n}=d_{n} x_{n}+e_{n} T x_{n}+f_{n} w_{n},
\end{gathered}
$$

is called the Noor iterative procedure with errors [11], where $\alpha_{n}, \beta_{n}, \gamma_{n}, a_{n}, b_{n}, c_{n}, d_{n}, e_{n}$, and $f_{n}$ are appropriate sequences in $[0,1]$ with $\alpha_{n}+\beta_{n}+\gamma_{n}=a_{n}+b_{n}+c_{n}=d_{n}+e_{n}+f_{n}=$ $1, n \geq 0$ and $\left\{u_{n}\right\},\left\{v_{n}\right\}$, and $\left\{w_{n}\right\}$ are bounded sequences in $C$. If $d_{n}=1\left(e_{n}=f_{n}=\right.$ 0 ), $n \geq 0$ then (1.1) reduces to the Ishikawa iterative procedure with errors [15] defined as follows:

$$
\begin{gathered}
x_{0} \in C, \\
x_{n+1}=\alpha_{n} x_{n}+\beta_{n} T y_{n}+\gamma_{n} u_{n}, \quad n \geq 0, \\
y_{n}=a_{n} x_{n}+b_{n} T x_{n}+c_{n} v_{n} .
\end{gathered}
$$

If $a_{n}=1\left(b_{n}=c_{n}=0\right)$ then (1.2) reduces to the following Mann type iterative procedure with errors [15]:

$$
\begin{gathered}
x_{0} \in C, \\
x_{n+1}=\alpha_{n} x_{n}+\beta_{n} T x_{n}+\gamma_{n} u_{n}, \quad n \geq 0 .
\end{gathered}
$$

Let $(E, d)$ be a metric space. A mapping $T: E \rightarrow E$ is said to be asymptotically nonexpansive, if there exists a sequence $\left\{K_{n}\right\} \in[1, \infty], \lim _{n \rightarrow \infty} K_{n}=1$, such that

$$
d\left(T^{n} x, T^{n} y\right) \leq K_{n} d(x, y), \quad \forall x, y \in E, \quad n \geq 0 .
$$

Let $F(T)$ be the set of fixed points of $T$ in $E$ and $F(T) \neq \emptyset$, a mapping $T$ is said to be asymptotically quasi-nonexpansive, if there exists $\left\{K_{n}\right\} \subset[1, \infty)$ with $\lim _{n \rightarrow \infty} K_{n}=1$ such that

$$
d\left(T^{n} x, p\right) \leq K_{n} d(x, p), \quad \forall x \in E, \quad p \in F(T), n \geq 0 .
$$


Moreover, $T$ is said to be uniformly quasi-Lipschitzian, if there exists $L>0$ such that

$$
d\left(T^{n} x, p\right) \leq L d(x, p), \quad \forall x \in E, p \in F(T), \quad n \geq 0 .
$$

Remark 1.1. If $F(T)$ is nonempty, then it follows from the above definitions that an asymptotically nonexpansive mapping must be asymptotically quasi-nonexpansive, and an asymptotically quasi-nonexpansive mapping must be a uniformly quasi-Lipschitzian with $L=\sup _{n \geq 0}\left\{K_{n}\right\}<\infty$. However, the inverse is not true in general.

Definition 1.2 (see [9]). Let $(E, d)$ be a metric space, and let $I=[0,1],\left\{\alpha_{n}\right\},\left\{\beta_{n}\right\},\left\{\gamma_{n}\right\}$ be real sequences in $[0,1]$ with $\alpha_{n}+\beta_{n}+\gamma_{n}=1$. A mapping $W: E^{3} \times I^{3} \rightarrow X$ is said to be a convex structure on $E$ if, for any $\left(x, y, z, \alpha_{n}, \beta_{n}, \gamma_{n}\right) \in E^{3} \times I^{3}$ and $u \in E$,

$$
d\left(W\left(x, y, z, \alpha_{n}, \beta_{n}, \gamma_{n}\right) u\right) \leq \alpha_{n} d(x, u)+\beta_{n} d(y, u)+\gamma_{n} d(z, u)
$$

If $(E, d)$ is a metric space with a convex structure $W$, then $(E, d)$ is called a convex metric space. Let $(E, d)$ be a convex metric space, a nonempty subset $C$ of $E$ is said to be convex if

$$
W\left(x, y, z, \lambda_{1}, \lambda_{2}, \lambda_{3}\right) \in C, \quad \forall\left(x, y, z, \lambda_{1}, \lambda_{2}, \lambda_{3}\right) \in C^{3} \times I^{3}
$$

Definition 1.3. Let $(E, d)$ be a convex metric space with a convex structure $W: E^{3} \times I^{3}$ and $T_{i}: E \rightarrow E$ be a finite family of uniformly quasi-Lipschitzian mappings with $i=1,2, \ldots, N$. Let $\left\{\alpha_{n}\right\},\left\{\beta_{n}\right\},\left\{\gamma_{n}\right\},\left\{a_{n}\right\},\left\{b_{n}\right\},\left\{c_{n}\right\},\left\{d_{n}\right\},\left\{e_{n}\right\}$, and $\left\{f_{n}\right\}$ be nine sequences in $[0,1]$ with

$$
\alpha_{n}+\beta_{n}+\eta_{n}=a_{n}+b_{n}+c_{n}=d_{n}+e_{n}+f_{n}=1, \quad n=0,1,2, \ldots
$$

For a given $x_{0} \in E$, define a sequence $\left\{x_{n}\right\}$ as follows:

$$
\begin{gathered}
x_{n+1}=W\left(x_{n}, T_{n}^{n} y_{n}, u_{n} ; \alpha_{n}, \beta_{n}, \gamma_{n}\right), \quad n \geq 0, \\
y_{n}=W\left(f\left(x_{n}\right), T_{n}^{n} z_{n}, v_{n} ; a_{n}, b_{n}, c_{n}\right), \\
z_{n}=W\left(f\left(x_{n}\right), T_{n}^{n} x_{n}, w_{n} ; d_{n}, e_{n}, f_{n}\right),
\end{gathered}
$$

where $T_{n}^{n}=T_{n(\bmod N)^{\prime}}^{n} f: E \rightarrow E$ is a Lipschitz continuous mapping with a Lipschitz constant $\xi>0$ and $\left\{u_{n}\right\},\left\{v_{n}\right\},\left\{w_{n}\right\}$ are any given three sequences in $E$. Then $\left\{x_{n}\right\}$ is called the Noor-type iterative sequence with errors for a finite family of uniformly quasi-Lipschitzian mappings $\left\{T_{i}\right\}_{i=1}^{N}$. If $f=I$ (the identity mapping on $E$ ) in (1.10), then the sequence $\left\{x_{n}\right\}$ defined by (1.10) can be written as follows:

$$
\begin{gathered}
x_{n+1}=W\left(x_{n}, T_{n}^{n} y_{n}, u_{n} ; \alpha_{n}, \beta_{n}, \gamma_{n}\right), \quad n \geq 0 ; \\
y_{n}=W\left(x_{n}, T_{n}^{n} z_{n}, v_{n} ; a_{n}, b_{n}, c_{n}\right), \\
z_{n}=W\left(x_{n}, T_{n}^{n} x_{n}, w_{n} ; d_{n}, e_{n}, f_{n}\right) .
\end{gathered}
$$


If $d_{n}=1$ for all $n \geq 0$ in (1.10), then $z_{n}=x_{n}$ for all $n \geq 0$ and the sequence $\left\{x_{n}\right\}$ defined by (1.10) can be written as follows:

$$
\begin{aligned}
x_{n+1} & =W\left(f\left(x_{n}\right), T_{n}^{n} y_{n}, u_{n} ; \alpha_{n}, \beta_{n}, \gamma_{n}\right), \quad n \geq 0, \\
y_{n} & =W\left(f\left(x_{n}\right), T_{n}^{n} x_{n}, v_{n} ; a_{n}, b_{n}, c_{n}\right) .
\end{aligned}
$$

If $f=I$ and $d_{n}=1$ for all $n \geq 0$, then the sequence $\left\{x_{n}\right\}$ defined by (1.10) can be written as follows:

$$
\begin{aligned}
x_{n+1} & =W\left(x_{n}, T_{n}^{n} y_{n}, u_{n} ; \alpha_{n}, \beta_{n}, \gamma_{n}\right), \quad n \geq 0, \\
y_{n} & =W\left(x_{n}, T_{n}^{n} x_{n}, v_{n} ; a_{n}, b_{n}, c_{n}\right),
\end{aligned}
$$

which is the Ishikawa type iterative sequence with errors considered in [9]. Further, if $f=I$ and $d_{n}=a_{n}=1$ for all $n \geq 0$, then $z_{n}=y_{n}=x_{n}$ for all $n \geq 0$ and (1.10) reduces to the following Mann type iterative sequence with errors [9]:

$$
x_{n+1} \equiv W\left(x_{n}, T_{n}^{n} x_{n}, u_{n} ; \alpha_{n}, \beta_{n}, \gamma_{n}\right), \quad n \geq 0
$$

In order to prove our main results, the following lemmas will be needed.

Lemma 1.4. Let $(E, d)$ be a convex metric space, $T_{i}: E \rightarrow E$ be a uniformly quasi-Lipschitzian mapping for $i=1,2, \ldots, N$ such that $F:=\bigcap_{i=1}^{N} F\left(T_{i}\right) \neq \emptyset$. Then there exists a constant $L \geq 1$ such that, for all $i=1,2, \ldots, N$,

$$
d\left(T_{i}^{n} x, p\right) \leq L d(x, p), \quad \forall x \in X, p \in F, n \geq 0
$$

Proof. In fact, for each $i=1,2, \ldots, N$, since $T_{i}: E \rightarrow E$ is a uniformly quasi-Lipschitzian mapping, we have

$$
d\left(T_{i}^{n} x, p\right) \leq L_{i} d(x, p) \leq L d(x, p), \quad \forall x \in E, p \in F, n \geq 0,
$$

where

$$
L=\max _{i=1,2, \ldots, N}\left\{\max \left\{L_{i}, 1\right\}\right\}
$$

This completes the proof. 
Lemma 1.5 (see [7]). Let $\left\{p_{n}\right\},\left\{q_{n}\right\},\left\{r_{n}\right\}$ be three nonexpansive squences satisfying the following conditions:

$$
p_{n+1} \leq\left(1+q_{n}\right) p_{n}+r_{n}, \quad \forall n \geq 0, \quad \sum_{n=0}^{\infty} q_{n}<\infty, \quad \sum_{n=0}^{\infty} r_{n}<\infty .
$$

Then

(1) $\lim _{n \rightarrow \infty} p_{n}$ exists;

(2) In addition, if $\liminf _{n \rightarrow \infty} p_{n}=0$, then $\lim _{n \rightarrow \infty} p_{n}=0$.

Lemma 1.6. Let $(E, d)$ be a complete convex metric space and $C$ be a nonempty closed convex subset of $E$. Let $T_{i}: C \rightarrow C$ be a finite family of uniformly quasi-Lipschitzian mapping for $i=1,2, \ldots, N$ such that $F:=\bigcap_{i=1}^{N} F\left(T_{i}\right) \neq \emptyset$ and $f: C \rightarrow C$ be a contractive mapping with a contractive constant $\xi \in(0,1)$.Let $\left\{x_{n}\right\}$ be the iterative sequence with errors defined by (1.10) and $\left\{u_{n}\right\},\left\{v_{n}\right\},\left\{w_{n}\right\}$ be three bounded sequences in $C$. Let $\left\{\alpha_{n}\right\},\left\{\beta_{n}\right\},\left\{\gamma_{n}\right\},\left\{a_{n}\right\},\left\{b_{n}\right\},\left\{c_{n}\right\},\left\{d_{n}\right\},\left\{e_{n}\right\},\left\{f_{n}\right\}$ be sequences in $[0,1]$ satisfying the following conditions:

(i) $\alpha_{n}+\beta_{n}+\gamma_{n}=a_{n}+b_{n}+c_{n}=d_{n}+e_{n}+f_{n}=1, \quad \forall n \geq 0 ;$

(ii) $\sum_{n=0}^{\infty}\left(\beta_{n}+\gamma_{n}\right)<\infty$;

(iii) $M_{0}=\operatorname{Sup}_{p \in F, n \geq 0}\left\{d\left(u_{n}, p\right)+d\left(v_{n}, p\right)+d\left(w_{n}, p\right)+d(f(p), p)\right\}<\infty$.

Then the following conclusions hold:

(1) for all $p \in F$ and $n \geq 0$,

$$
d\left(x_{n+1}, p\right) \leq\left[1+\beta_{n} L\left(1+L+L^{2}\right)\right] d\left(x_{n}, p\right)+M \eta_{n}
$$

where $L=\max _{i=1,2, \ldots, N}\left\{L_{i}\right\}, \eta_{n}=\beta_{n}+\gamma_{n}$ for all $n \geq 0$ and

$$
M=L(1+L)\left[d\left(u_{n}, p\right)+d\left(v_{n}, p\right)+d\left(w_{n}, p\right)+d(f(p), p)\right]
$$

(2) there exists a constant $M_{i}>0$ such that

$$
d\left(x_{n+m}, p\right) \leq M_{1} d\left(x_{n}, p\right)+M M_{1} \sum_{k=n}^{n+m-1} \eta_{k}, \quad \forall p \in F,
$$

for all $n, m \geq 0$. 
Proof. (1) It follows from (1.7),(1.10), and Lemma 1.4 that

$$
\begin{aligned}
d\left(x_{n+1}, p\right) & =d\left(W\left(x_{n}, T_{n}^{n} y_{n}, u_{n} ; \alpha_{n}, \beta_{n}, \gamma_{n}\right), p\right) \\
& \leq \alpha_{n} d\left(x_{n}, p\right)+\beta_{n} d\left(T_{n}^{n} y_{n}, p\right)+\gamma_{n} d\left(u_{n}, p\right) \\
& \leq \alpha_{n} d\left(x_{n}, p\right)+\beta_{n} L d\left(y_{n}, p\right)+\gamma_{n} d\left(u_{n}, p\right), \\
d\left(y_{n}, p\right) & =d\left(W\left(f\left(x_{n}\right), T_{n}^{n} z_{n}, v_{n} ; a_{n}, b_{n}, c_{n}\right), p\right) \\
& \leq a_{n} d\left(f\left(x_{n}\right), p\right)+b_{n} d\left(T_{n}^{n} z_{n}, p\right)+c_{n} d\left(v_{n}, p\right) \\
& \leq a_{n} d\left(f\left(x_{n}\right), f(p)\right)+a_{n} d(f(p), p)+b_{n} L d\left(z_{n}, p\right)+c_{n} d\left(v_{n}, p\right) \\
& \leq a_{n} \xi d\left(x_{n}, p\right)+a_{n} d(f(p), p)+b_{n} L d\left(z_{n}, p\right)+c_{n} d\left(v_{n}, p\right), \\
d\left(z_{n}, p\right) & =d\left(W\left(f\left(x_{n}\right), T_{n}^{n} x_{n}, w_{n} ; d_{n}, e_{n}, f_{n}\right), p\right) \\
& \leq d_{n} d\left(f\left(x_{n}\right), p\right)+e_{n} d\left(T_{n}^{n} x_{n}, p\right)+f_{n} d\left(w_{n}, p\right) \\
& \leq d_{n} d\left(f\left(x_{n}\right), f(p)\right)+d_{n} d(f(p), p)+e_{n} L d\left(x_{n}, p\right)+f_{n} d\left(w_{n}, p\right) \\
& \leq d_{n} \xi d\left(x_{n}, p\right)+d_{n} d(f(p), p)+e_{n} L d\left(x_{n}, p\right)+f_{n} d\left(w_{n}, p\right) \\
& \leq\left(d_{n} \xi+e_{n} L\right) d\left(x_{n}, p\right)+d_{n} d(f(p), p)+f_{n} d\left(w_{n}, p\right) .
\end{aligned}
$$

Substituting (1.23) into (1.22) and simplifying it, we have

$$
\begin{aligned}
d\left(x_{n+1}, p\right) \leq & \alpha_{n} d\left(x_{n}, p\right) \\
& +\beta_{n} L\left[a_{n} \xi d\left(x_{n}, p\right)+a_{n} d(f(p), p)+b_{n} L d\left(z_{n}, p\right)+c_{n} d\left(v_{n}, p\right)\right]+\gamma_{n} d\left(u_{n}, p\right) \\
\leq & \left(\alpha_{n}+\beta_{n} L \xi a_{n}\right) d\left(x_{n}, p\right)+\beta_{n} L a_{n} d(f(p), p) \\
& +\beta_{n} L^{2} b_{n} d\left(z_{n}, p\right)+\beta_{n} L c_{n} d\left(v_{n}, p\right)+\gamma_{n} d\left(u_{n}, p\right) .
\end{aligned}
$$

Substituting (1.24) into (1.25) and simplifying it, we get

$$
\begin{aligned}
d\left(x_{n+1}, p\right) \leq & \left(\alpha_{n}+\beta_{n} L a_{n} \xi\right) d\left(x_{n}, p\right) \\
& +\beta_{n} L^{2} b_{n}\left[\left(d_{n} \xi+e_{n} L\right) d_{n}\left(x_{n}, p\right)+d_{n} d(f(p), p)+f_{n} d\left(w_{n}, p\right)\right] \\
& +\beta_{n} L a_{n} d(f(p), p)+\beta_{n} L c_{n} d\left(v_{n}, p\right)+\gamma_{n} d\left(u_{n}, p\right) \\
= & \left\{\alpha_{n}+\beta_{n} L\left[a_{n} \xi+L b_{n}\left(d_{n} \xi+e_{n} L\right)\right]\right\} d\left(x_{n}, p\right)+\beta_{n} L^{2} b_{n} d_{n} d(f(p), p) \\
& +\beta_{n} L a_{n} d(f(p), p)+\beta_{n} L^{2} b_{n} f_{n} d\left(w_{n}, p\right)+\beta_{n} L c_{n} d\left(v_{n}, p\right)+\gamma_{n} d\left(u_{n}, p\right)
\end{aligned}
$$


Fixed Point Theory and Applications

$$
\begin{aligned}
\leq & {\left[1+\beta_{n} L\left(1+L+L^{2}\right)\right] d\left(x_{n}, p\right)+\left[\beta_{n} L^{2} b_{n} d_{n}+\beta_{n} L a_{n}\right] d(f(p), p)+\gamma_{n} d\left(u_{n}, p\right) } \\
& +\beta_{n} L c_{n} d\left(v_{n}, p\right)+\beta_{n} L^{2} b_{n} f_{n} d\left(w_{n}, p\right) \\
\leq & {\left[1+\beta_{n} L\left(1+L+L^{2}\right)\right] d\left(x_{n}, p\right)+\beta_{n} L(1+L) d(f(p), p)+\gamma_{n} L(1+L) d(f(p), p) } \\
& +L(1+L)\left(\beta_{n}+\gamma_{n}\right) d\left(u_{n}, p\right)+L(1+L)\left(\beta_{n}+\gamma_{n}\right) d\left(v_{n}, p\right) \\
& +L(1+L)\left(\beta_{n}+\gamma_{n}\right) d\left(w_{n}, p\right) \\
= & {\left[1+\beta_{n} L\left(1+L+L^{2}\right)\right] d\left(x_{n}, p\right) } \\
& +L(1+L)\left(\beta_{n}+\gamma_{n}\right)\left[d\left(u_{n}, p\right)+d\left(v_{n}, p\right)+d\left(w_{n}, p\right)+d(f(p), p)\right] \\
= & {\left[1+\beta_{n} L\left(1+L+L^{2}\right)\right] d\left(x_{n}, p\right)+M \eta_{n}, \quad \forall n \geq 0, p \in F, }
\end{aligned}
$$

where

$$
M=L(1+L)\left[d\left(u_{n}, p\right)+d\left(v_{n}, p\right)+d\left(w_{n}, p\right)+d(f(p), p)\right], \quad \eta_{n}=\beta_{n}+\gamma_{n} .
$$

(2) Since $1+x \leq e^{x}$ for all $x \geq 0$, it follows from (1.26) that, for $n, m \geq 0$ and $p \in F$,

$$
\begin{aligned}
d\left(x_{n+m}, p\right) & \leq\left[1+\beta_{n+m-1} L\left(1+L+L^{2}\right)\right] d\left(x_{n+m-1}, p\right)+M \eta_{n+m-1} \\
& \leq e^{\beta_{n+m-1} L\left(1+L+L^{2}\right)} d\left(x_{n+m-1}, p\right)+M \eta_{n+m-1} \\
& \leq e^{\beta_{n+m-1} L\left(1+L+L^{2}\right)}\left\{\left[1+\beta_{n+m-2} L\left(1+L+L^{2}\right)\right] d\left(x_{n+m-2}, p\right)+M \eta_{n+m-2}\right\}+M \eta_{n+m-1} \\
& \leq e^{L\left(1+L+L^{2}\right)\left(\beta_{n+m-1}+\beta_{n+m-2}\right)} d\left(x_{n+m-1}, p\right)+M\left[e^{\beta_{n+m-1} L\left(1+L+L^{2}\right)} \eta_{n+m-2}+\eta_{n+m-1}\right] \\
& \leq \cdots \\
& \leq M_{1} d\left(x_{n}, p\right)+M_{1} M \sum_{k=n}^{n+m-1} \eta_{k}
\end{aligned}
$$

where

$$
M_{1}=e^{L\left(1+L+L^{2}\right)} \sum_{k=0}^{\infty} \beta_{k} .
$$

This completes the proof. 


\section{Main Results}

Theorem 2.1. Let $(E, d)$ be a complete convex metric space and $C$ be a nonempty closed convex subset of $E$. Let $T_{i}: C \rightarrow C$ be a finite family of uniformly quasi-Lipschitzian mapping for $i=1,2, \ldots, N$ such that $F:=\bigcap_{i=1}^{N} F\left(T_{i}\right) \neq \emptyset$ and $f: C \rightarrow C$ be a contractive mapping with a contractive constant $\xi \in(0,1)$. Let $\left\{x_{n}\right\}$ be the iterative sequence with errors defined by $(1.10)$ and $\left\{u_{n}\right\},\left\{v_{n}\right\},\left\{w_{n}\right\}$ be three bounded sequence in $C$ and $\left\{\alpha_{n}\right\},\left\{\beta_{n}\right\},\left\{\gamma_{n}\right\},\left\{a_{n}\right\},\left\{b_{n}\right\},\left\{c_{n}\right\},\left\{d_{n}\right\},\left\{e_{n}\right\}$ and $\left\{f_{n}\right\}$ be nine sequences in $[0,1]$ satisfying the following conditions:

(i) $\alpha_{n}+\beta_{n}+\gamma_{n}=a_{n}+b_{n}+c_{n}=d_{n}+e_{n}+f_{n}=1, \forall n \geq 0$,

(ii) $\sum_{n=0}^{\infty}\left(\beta_{n}+\gamma_{n}\right)<\infty$,

(iii) $M_{0}=\operatorname{Sup}_{p \in F, n \geq 0}\left\{d\left(u_{n}, p\right)+d\left(v_{n}, p\right)+d\left(w_{n}, p\right)+d(f(p), p)\right\}<\infty$.

Then the sequence $\left\{x_{n}\right\}$ converges to a common fixed point $p \in F$ if and only if $\liminf _{n \rightarrow \infty} d\left(x_{n}, F\right)=0$, where $d(x, F)=\inf \{d(x, F), p \in F\}$.

Proof. The necessity is obvious. Now prove the sufficiency. In fact, from Lemma 1.6, we have

$$
d\left(x_{n+1}, F\right) \leq\left[1+\beta_{n} L\left(1+L+L^{2}\right)\right] d\left(x_{n}, F\right)+M \eta_{n}, \quad \forall n \geq 0,
$$

where $\eta_{n}=\beta_{n}+\gamma_{n}$. By conditions (i) and (ii), we know that

$$
\sum_{n=0}^{\infty} \eta_{n}<\infty, \quad \sum_{n=0}^{\infty} \beta_{n}<\infty
$$

It follows from Lemma 1.5 that $\lim _{n \rightarrow \infty} d\left(x_{n}, F\right)$ exists. Since $\liminf _{n \rightarrow \infty} d\left(x_{n}, F\right)=0$, we have

$$
\lim _{n \rightarrow \infty} d\left(x_{n}, F\right)=0
$$

Next prove that $\left\{x_{n}\right\}$ is a Cauchy sequence in $C$. In fact, for any given $\varepsilon>0$, there exists a positive integer $N_{0}$ such that

$$
d\left(x_{n}, F\right) \leq \frac{\varepsilon}{8 M_{1}}, \quad \sum_{n=N_{0}}^{\infty} \eta_{n} \leq \frac{\varepsilon}{4 M_{1} M^{\prime}}, \quad \forall n \geq 0 .
$$

From (2.4), there exist $p_{1} \in F$ and positive integer $N_{1}>N_{0}$ such that

$$
d\left(x_{N_{1}}, p_{1}\right)<\frac{\varepsilon}{4 M_{1}} .
$$


Thus Lemma 1.6 implies that, for any positive integers $n, m$ with $n>N_{1}$,

$$
\begin{aligned}
d\left(x_{n+m}, x_{n}\right) & \leq d\left(x_{n+m}, p_{1}\right)+d\left(p_{1}, x_{n}\right) \\
& \leq M_{1} d\left(x_{N_{1}}, P_{1}\right)+M_{1} M \sum_{k=N_{1}}^{n+m-1} \eta_{k}+M_{1} d\left(x_{N_{1}}, p_{1}\right)+M_{1} M \sum_{k=N_{1}}^{n-1} \eta_{k} \\
& \leq 2 M_{1} \frac{\varepsilon}{4 M_{1}}+2 M_{1} M \frac{\varepsilon}{4 M_{1} M} \\
& =\varepsilon .
\end{aligned}
$$

This shows that $\left\{x_{n}\right\}$ is a Cauchy sequence in a nonempty closed convex subset $C$ of a complete convex metric space $E$. Without loss of generality, we can assume that $\lim _{n \rightarrow \infty} x_{n}=$ $p^{*} \in E$. Next prove that $p^{*} \in F$. In fact, for any given $\varepsilon^{\prime}>0$, there exists a positive integer $N_{2}$ such that for all $n \geq N_{2}$,

$$
d\left(x_{n}, p^{*}\right) \leq \frac{\varepsilon^{\prime}}{4 L}, \quad d\left(x_{n}, F\right) \leq \frac{\varepsilon^{\prime}}{8 L} .
$$

Again from (2.7), there exist $p_{2} \in F$ and positive integer $N_{3}>N$ such that

$$
d\left(x_{N_{3}}, P_{2}\right) \leq \frac{\varepsilon^{\prime}}{4 L}
$$

Thus, for any $i=1,2, \ldots, N$, from (2.7) and (2.8), we have

$$
\begin{aligned}
d\left(T_{i} P^{*}, P^{*}\right) & \leq d\left(T_{i} P^{*}, P_{2}\right)+d\left(P_{2}, T_{i} x_{N_{3}}\right)+d\left(T_{i} x_{N_{3}}, P^{*}\right) \\
& \leq L d\left(P^{*}, p_{2}\right)+\operatorname{Ld}\left(p_{2}, x_{N_{3}}\right)+\operatorname{Ld}\left(x_{N_{3}}, P^{*}\right) \\
& \leq L\left\{d\left(P^{*}, x_{N_{3}}\right)+d\left(x_{N_{3}}, p_{2}\right)\right\}+\operatorname{Ld}\left(p_{2}, x_{N_{3}}\right)+\operatorname{Ld}\left(x_{N_{3}}, P^{*}\right) \\
& =2 L d\left(P^{*}, x_{N_{3}}\right)+2 L d\left(x_{N_{3}}, p_{2}\right) \\
& <\frac{\varepsilon^{\prime}}{2}+\frac{\varepsilon^{\prime}}{2}=\varepsilon^{\prime} .
\end{aligned}
$$

By the arbitrariness of $\varepsilon^{\prime}>0$, we know that $T_{i} P^{*}=P^{*}$ for all $i=1,2, \ldots, N$, that is, $p^{*} \in F$. This completes the proof of Theorem 2.1.

Taking $f=I$ in Theorem 2.1, then we have the following theorem.

Theorem 2.2. Let $(E, d)$ be a complete convex metric space and $C$ be a nonempty closed convex subset of $E$. Let $T_{i}: C \rightarrow C$ be a finite family of uniformly quasi-Lipschitzian mapping for $i=1,2, \ldots, N$ such that $F:=\bigcap_{i=1}^{N} F\left(T_{i}\right) \neq \emptyset$. Let $\left\{x_{n}\right\}$ be the iterative sequence with errors defined by (1.11) and $\left\{u_{n}\right\},\left\{v_{n}\right\},\left\{w_{n}\right\}$ be three bounded sequence in $C$, and $\left\{\alpha_{n}\right\},\left\{\beta_{n}\right\},\left\{\gamma_{n}\right\},\left\{a_{n}\right\},\left\{b_{n}\right\},\left\{c_{n}\right\},\left\{d_{n}\right\},\left\{e_{n}\right\}$, and $\left\{f_{n}\right\}$ be nine sequence in $[0,1]$ satisfying the 
conditions (i)-(iii) of Theorem 2.1. Then the sequence $\left\{x_{n}\right\}$ converges to a common fixed point $p \in F$ if and only if

$$
\liminf _{n \rightarrow \infty} d\left(x_{n}, F\right)=0 \text {, }
$$

where $d(x, F)=\inf \{d(x, F), p \in F\}$.

Taking $d_{n}=1$ in Theorem 2.1, then we have the following theorem.

Theorem 2.3. Let $(E, d)$ be a complete convex metric space and $C$ be a nonempty closed convex subset of $E$. Let $T_{i}: C \rightarrow C$ be a finite family of uniformly quasi-Lipschitzian mapping for $i=1,2, \ldots, N$ such that $F:=\bigcap_{i=1}^{N} F\left(T_{i}\right) \neq \emptyset$ and $f: C \rightarrow C$ be a contractive mapping with a contractive constant $\xi \in(0,1)$. Let $\left\{x_{n}\right\}$ be the iterative sequence with errors defined by (1.12) and $\left\{u_{n}\right\},\left\{v_{n}\right\}$ be two bounded sequences in $C$ and $\left\{\alpha_{n}\right\},\left\{\beta_{n}\right\},\left\{\gamma_{n}\right\},\left\{a_{n}\right\},\left\{b_{n}\right\},\left\{c_{n}\right\}$ be nine sequences in $[0,1]$ satisfying the conditions (ii) and (iii) of Theorem 2.1 and $\alpha_{n}+\beta_{n}+\gamma_{n}=a_{n}+b_{n}+c_{n}=1$ for all $n \geq 0$. Then the sequence $\left\{x_{n}\right\}$ converges to a common fixed point $p \in F$ if and only if

$$
\liminf _{n \rightarrow \infty} d\left(x_{n}, F\right)=0,
$$

where $d(x, F)=\inf \{d(x, p), p \in F\}$.

Remark 2.4. Theorems 2.1-2.3 generalize, improve, and unify some corresponding results in [1-14].

Similarly, we can obtain the following results.

Theorem 2.5. Let $(E, d)$ be a complete convex metric space and $C$ be a nonempty closed convex subset of E. Let $T_{i}: C \rightarrow C$ be a finite family of asymptotically quasi-nonexpansive mapping for $i=1,2, \ldots, N$ such that $F:=\bigcap_{i=1}^{N} F\left(T_{i}\right) \neq \emptyset$ and $f: C \rightarrow C$ be a contractive mapping with $a$ contractive constant $\xi \in(0,1)$. Let $\left\{x_{n}\right\}$ be the iterative sequence with errors defined by (1.10) and $\left\{u_{n}\right\},\left\{v_{n}\right\},\left\{w_{n}\right\}$ be three bounded sequences in $C$ and $\left\{\alpha_{n}\right\},\left\{\beta_{n}\right\},\left\{\gamma_{n}\right\},\left\{a_{n}\right\},\left\{b_{n}\right\},\left\{c_{n}\right\},\left\{d_{n}\right\},\left\{e_{n}\right\}$, and $\left\{f_{n}\right\}$ be nine sequences in [0,1] satisfying the conditions (i)-(iii) of Theorem 2.1. Then the sequence $\left\{x_{n}\right\}$ converges to a common fixed point $p \in F$ if and only if

$$
\liminf _{n \rightarrow \infty} d\left(x_{n}, F\right)=0 \text {, }
$$

where $d(x, F)=\inf f\{d(x, p), p \in F\}$.

Proof. From Remark 1.1, we know that each asymptotically quasi-nonexpansive mapping $T_{i}$ : $C \rightarrow C, i=1,2, \ldots, N$ must be a uniformly quasi-Lipschitzian with

$$
L_{i}=\operatorname{Sup}_{n \geq 0}\left\{k_{n}^{(i)}\right\}<\infty,
$$

where $\left\{k_{n}^{(i)}\right\} \subset[1, \infty)$ is the sequence appeared in (1.5). Hence the conclusion of Theorem 2.5 can be obtained from Theorem 2.1 immediately. This completes the proof. 
Theorem 2.6. Let $(E, d)$ be a complete convex metric space and $C$ be a nonempty closed convex subset of $E$. Let $T_{i}: C \rightarrow C$ be a finite family of asymptotically quasi-nonexpansive mapping for, $i=1,2, \ldots, N$ such that $F:=\bigcap_{i=1}^{N} F\left(T_{i}\right) \neq \emptyset$. Let $\left\{x_{n}\right\}$ be the iterative sequence with errors defined by (1.11) and $\left\{u_{n}\right\},\left\{v_{n}\right\},\left\{w_{n}\right\}$ be three bounded sequence in $C$ and $\left\{\alpha_{n}\right\},\left\{\beta_{n}\right\},\left\{\gamma_{n}\right\},\left\{a_{n}\right\},\left\{b_{n}\right\},\left\{c_{n}\right\},\left\{d_{n}\right\},\left\{e_{n}\right\}$, and $\left\{f_{n}\right\}$ be nine sequence in $[0,1]$ satisfying the conditions (i)-(iii) of Theorem 2.1. Then the sequence $\left\{x_{n}\right\}$ converges to a common fixed point $p \in F$ if and only if

$$
\liminf _{n \rightarrow \infty} d\left(x_{n}, F\right)=0
$$

where $d(x, F)=\inf \{d(x, p), p \in F\}$.

\section{Acknowledgment}

The authors would like to express their thanks to the referees for their helpful comments and suggestions.

\section{References}

[1] W. Takahashi, "A convexity in metric space and nonexpansive mappings. I," Kōdai Mathematical Seminar Reports, vol. 22, pp. 142-149, 1970.

[2] W. A. Kirk, "Krasnoselskii's iteration process in hyperbolic space," Numerical Functional Analysis and Optimization, vol. 4, no. 4, pp. 371-381, 1982.

[3] K. Goebel and W. A. Kirk, "Iteration processes for nonexpansive mappings," in Topological Methods in Nonlinear Functional Analysis (Toronto, Canada, 1982), vol. 21 of Contemporary Mathematics, pp. 115-123, American Mathematical Society, Providence, RI, USA, 1983.

[4] W. V. Petryshyn and T. E. Williamson, Jr., "Strong and weak convergence of the sequence of successive approximations for quasi-nonexpansive mappings," Journal of Mathematical Analysis and Applications, vol. 43, pp. 459-497, 1973.

[5] M. K. Ghosh and L. Debnath, "Convergence of Ishikawa iterates of quasi-nonexpansive mappings," Journal of Mathematical Analysis and Applications, vol. 207, no. 1, pp. 96-103, 1997.

[6] Q. Liu, "Iterative sequences for asymptotically quasi-nonexpansive mappings," Journal of Mathematical Analysis and Applications, vol. 259, no. 1, pp. 1-7, 2001.

[7] Q. Liu, "Iterative sequences for asymptotically quasi-nonexpansive mappings with error member," Journal of Mathematical Analysis and Applications, vol. 259, no. 1, pp. 18-24, 2001.

[8] Q. Liu, "Iteration sequences for asymptotically quasi-nonexpansive mapping with an error member of uniform convex Banach space," Journal of Mathematical Analysis and Applications, vol. 266, no. 2, pp. 468-471, 2002.

[9] Y.-X. Tian, "Convergence of an Ishikawa type iterative scheme for asymptotically quasi-nonexpansive mappings," Computers E Mathematics with Applications, vol. 49, no. 11-12, pp. 1905-1912, 2005.

[10] C. Wang and L. W. Liu, "Convergence theorems for fixed points of uniformly quasi-Lipschitzian mappings in convex metric spaces," Nonlinear Analysis: Theory, Methods E Applications, vol. 70, no. 5, pp. 2067-2071, 2009.

[11] Y. J. Cho, H. Zhou, and G. Guo, "Weak and strong convergence theorems for three-step iterations with errors for asymptotically nonexpansive mappings," Computers E Mathematics with Applications, vol. 47, no. 4-5, pp. 707-717, 2004.

[12] H. Fukhar-ud-din and S. H. Khan, "Convergence of iterates with errors of asymptotically quasinonexpansive mappings and applications," Journal of Mathematical Analysis and Applications, vol. 328 , no. 2, pp. 821-829, 2007.

[13] J. U. Jeong and S. H. Kim, “Weak and strong convergence of the Ishikawa iteration process with errors for two asymptotically nonexpansive mappings," Applied Mathematics and Computation, vol. 181, no. 2, pp. 1394-1401, 2006. 
[14] H. Zhou, J. I. Kang, S. M. Kang, and Y. J. Cho, "Convergence theorems for uniformly quasiLipschitzian mappings," International Journal of Mathematics and Mathematical Science, vol. 2004, no. 15, pp. 763-775, 2004.

[15] Y. Xu, "Ishikawa and Mann iterative processes with errors for nonlinear strongly accretive operator equations," Journal of Mathematical Analysis and Applications, vol. 224, no. 1, pp. 91-101, 1998. 